\title{
Medical Malfunction: How Health Administrators can become more Receptive to the LGBT Community
}

\author{
Anthony A. Murphy ${ }^{\mathrm{a}}$
}

\begin{abstract}
What companies have begun to see over the past few years is the slow destruction of the metaphorical closet the Lesbian, Gay, Bisexual, and Transgender (LGBT) community has been confined to for the past century. Now that the federal government has taken a proactive stance against discrimination in the workplace based on sexual orientation and gender identity, it will be up to health administrators to implement their own policies that will assist employees and management in being more receptive to the needs of their LGBT workers. Here, you will find several procedures and strategies that can be put into practice by hospitals and clinics that make for a much more sensitive work environment. Combining these strategies into the culture of the workplace will increase productivity and decrease employee conflict and ostracizing among LGBT employees.
\end{abstract}

Keywords: Healthcare; LGBT; Employee Discrimination

It has been several months since President Barack Obama announced his administration would no longer be enforcing the Defense of Marriage Act. Since then, we have seen several more states legalize gay marriage, the Department of Defense end its controversial policy of "Don't Ask, Don't Tell", and what has become a growing "liberalization" among the United States population in granting rights to sexual minorities and the gender nonconforming (Donovan \& Tolbert, 2013). Traditional business models such as Intel, Nike, eBay, and similar Fortune 500 companies have been for the past several years constructing diversity education and training models for their employees who do not identify as Lesbian, Gay, Bisexual, or Transgender (LGBT) to give them a better understanding of the differences in sexual orientation and gender-variance. Many of these companies training modules are based on the work and consultation of corporate diversity consultant Brian McNaught (McNaught, 1993; 1997; 2010). Unfortunately, McNaught's suggestions have been primarily in the field of business administration and not in the complex, intricate environment associated with health administration. The healthcare industry has severely lagged behind in the progress toward diversity predominantly due to the multifaceted construct that encompasses healthcare organizations. In addition to the complex system that is the healthcare industry, studies have also found that nurses, practitioners, and administrators are permeated with both hidden and direct prejudices, uncomfortable with discussing LGBT issues, and are using obsolete medical practices on their LGBT patients (Kenagy, 2005; Herman, 2009; Rondahl, 2009; Wagner, et al., 2010). This has lead to misdiagnoses, unnecessary treatment, medical waste, as well as reports of discrimination taking shape in the form of refusal of care, bullying and even assault (Anne Jilson, 2002). Much of this is due to the staff's general assumptions that people are heterosexual, a social product of heteronormative culture. This is truly unfortunate because of the anomalous medical needs often required by patients of different sexual orientations and gender identity (Wagner, et al., 2010).

Healthcare facilities will have to follow suit with other industries in combating LGBT discrimination by further developing diversity educational programs that discuss sexual orientation and gender identity in a healthcare setting. Health administrators will now have the responsibility of having to understand the needs of their queer ${ }^{1}$ employees, while also respecting the concerns of other coworkers. Administrators wanting to teach more diversity to their clinicians and staff should begin to focus their efforts on creating a healthy environment by first acknowledging the components of the different sexual orientations and gender variations. Many of the recommendations in this paper will aid health administrators with workplace acceptance of queer employees that can eventually translate over into patient support.

This paper is intended to provide healthcare administrators with: (1) a descriptive analysis defining the differences between heteronormativity, heterosexism, and homophobia; (2) current studies from leading experts that outline ways and means to identify troubled queer employees who may be feeling isolated, ostracized, or who have disassociated themselves with the organization; (3) an update of proper terminology; and (4) strategies and techniques administrators can employ to increase LGBT inclusive awareness. An intuitive understanding of these discussions will aid health administrators in achieving a successful LGBT diversity training module that will assist in creating an open and receptive environment for employees and patients.

Many problems arise due to administrators, nurses, and physicians automatically assuming that an individual is heterosexual. (Rondahl, 2009). This is typically referred to as heteronormativity and if one can first remove this unintended postulation then one can then begin to understand the formal and informal discrimination that is imposed on employees. A

\footnotetext{
${ }^{1}$ Queer is an umbrella term that encompasses the Lesbian, Gay, Bisexual, and Transgender labels. The LGBT community has come to pride itself on taking back this term from the bigotry it once represented. It is now used frequently in referring to anything from 'queer politics' to 'queer theory'. The term will be used throughout the literature.
} 
heteronormative environment can lead to what has been labeled heterosexism-discriminating against someone who identifies as LGBT based on this assumption. It is important to distinguish the two terms heteronormative and heterosexism from homophobia, for the latter implies fear and hatred, where as the former could be simply be due to sheer thoughtlessness. For example, heteronormativity may lead a health administrator to assume every partnered individual in one's hospital has a spouse of the opposite sex - which would then lead to the heterosexist move of telling the men at your hospital to invite their wives or girlfriends to their party, thus leaving out any man who partnered to another man. This is a demonstration of obtuseness on the part of the administrator, not out of hate or fear, but still a way of 'othering' queer people in an organization.

Heterosexism can be damaging, although not to the extent of homophobia or transphobia. An administrator must be able to recognize the differences between homophobia and heterosexism. Where homophobia can be categorized as abhorrence to intimate relationships between two persons of the same gender, heterosexism is not a fear, but an unintended conjecture brought on by the socialization process. It is the norm for one to automatically presume that an individual is in a traditional heterosexual relationship (Rudacille, 2006; McNaught, 2010). It is these presumptions which must be eliminated in order for the queer community to become fully accepted in the workplace. In the words of McNaught (2010), "always allow for the probability that a gay person may be present." This is an excellent standard to follow and may prevent not only coworkers from being discriminated against, but suppliers and patients as well. Before a health administrator can substantially minimize heterosexism and homophobia, they must first identify what sorts of attitudes are common amongst employees who do not identify as LGBT.

Levels of attitudes towards queer individuals do tend to fluctuate (Riddle, 1985; Chung, 2001). Riddle (1985) discovered there are four negative levels-repulsion, pity, tolerance, and acceptance - and four positive levels - support, admiration, appreciation, and nurturance-of attitudes employees feel towards those who identify as LGBT. The scale was used to assess the continuum of attitudes towards queers in a general workplace culture. Although I will not discuss each one individually, let us look at what the attitudes represent as a whole. The negative attitudes used by some employees fail to view members of the LGBT community as equals. Even having an attitude of "acceptance" still implies that there is something to accept; and by implying such, an LGBT person is being segregated from the rest of his or her cohorts (Riddle, 1985). Diversity education will help employees have positive attitudes towards their gay and lesbian coworkers. Positive attitudes include being supportive and nurturing. A feeling of admiration is what human resource managers should strive to instill in their straight employees. Health administrators should want their staff to value the diversity of people and to see queers as indispensible to the organization.

Blumenfeld (1992) explained the ramifications of homophobia best when he stated that "at the same time the victims of prejudice are oppressed, the perpetrators... of the dominant group are hurt in some way as well. Although the effects of oppression differ for specific agent groups, in the end everyone loses." Thus, homophobia inhibits appreciation of other types of diversity, making it repressive for all parties involved and disallowing each person from being able to demonstrate their own unique traits. Therefore, all employees suffer when any one of them is disrespected. And because disrespect can come in all forms, it is important to be able to identify and control any sort of harassment.

Another step in moving forward with progress in vocational behavior is recognizing the coping strategies queer employees will exploit when they encounter real or potential discrimination. Knowing what coping strategies are typically used to combat discrimination can effectively create a positive environment for queer employees. The overall difficulty queers face within workplace culture is that LGBT employees tend be tolerated but not accepted (McNaught, 2010). When "tolerance" is the distinctive factor in the culture of a workplace it creates an ignorance-based anxiety about homosexuality (Chung, 2001; McNaught, 2010). Chung (2001) describes it best when he states that "tolerance [indicates] the presence of regulations against formal discrimination, but lacks informal support" (p. 34). It is very easy for queer employees to pick up on this anxiety amongst their cohorts, and as a result, many of them will create coping strategies in order to combat any prejudice, social oppression, or discrimination against them (Chung, 2001; Chung et al. 2009). What many organizations have begun to see is their queer employees taking on these coping strategies in response to both formal and informal discrimination (Levine \& Leonard, 1984; Chung, 2001). Coping strategies are exercised by the LGBT workforce to counteract workplace anxiety. Chung et al. (2009) expanded on his Discrimination Management model and found that there were sixteen coping strategies used by individuals to avoid discrimination. Some of these coping strategies are used more often than the others. For instance, coping strategies based on vocational choice that are used frequently are self-employment and job tracking (Levine and Leonard, 1984; Chung et al., 2009). Selfemployment was commonly used for years because according to Chung (2001), "this option [afforded] a person maximum freedom without the worry of being fired or discriminated against because of one's sexual orientation." As more workplaces have become more diversely aware, employees in the gay community have transitioned from utilizing selfemployment to job tracking. Queers tend to feel more comfortable around others of the same sexual orientation, so some will seek out employment where they are assured, either through a colleague or the media, that the institution to which they are applying with already has a large LGBT workforce (Levine \& Leonard, 1984; Chung, 2001; Chung et al., 2009). Job tracking can be used to a human resource manager's advantage as a motivating force to diversify their workplace culture. It certainly demonstrates the necessity for human resource managers to ensure a diverse work environment; otherwise, a business runs the risk of losing a potentially outstanding employee or clientele. Please keep in mind however, that an LGBT laborer can never rule out the possibility of discrimination even when self-employment and job tracking are utilized. Those who are self-employed still face possible discrimination from business partners or clients, while job tracking could fail to detect any informal discrimination. 
Informal discrimination can be common in a work environment and it oftentimes goes undetected. Once informal discrimination becomes apparent to a queer employee, they will begin to use work adjustment strategies to help cope (Griffin, 1992; Chung, 2001). Identity management has become common amongst LGB employees because they are what Fassinger (1991) calls "the invisible minority." Lesbian, Gay and Bisexual employees ${ }^{2}$ use this invisibility to their advantage through several other workplace survival mechanisms. Griffin (1992) originally identified these mechanisms as: acting, covering, passing, and implicitly and explicitly coming out. Examples of such are, one may "act" straight by engaging in heterosexual relationships so that other coworkers will make heterosexual assumptions. In addition, a gay man or lesbian woman may "cover" up their sexuality by avoiding or omitting certain words when talking about relationships. Chung et al. (2009) found that "passing" off as a heterosexual has become most common and is a way of concocting information so that one may not seem homosexual. For instance, a lesbian woman may use male names or pronouns when describing a date to coworkers, even though there may have never been a date or the date was with someone of the same sex. Something relatively healthier as a coping strategy for queer employees is used by those who are "implicitly out." This means an employee will be open and honest without necessarily labeling themselves as queer. A great example of this is if a bisexual man were to bring his male partner to a social function, but introduced the partner as his roommate. Lastly, and what is least common, is to be "explicitly out," meaning one openly identifies themselves as lesbian, gay, bisexual, or transgender (Chung, 2001; Chung et al., 2009). An example could be that a transgender individual tells his coworkers that he enjoys dressing as a female and performs nightly at shows around town. By adequately identifying forms of workplace discrimination and the coping strategies that accompany it, human resource managers will be able to conceptualize various forms of discrimination and can begin to develop plans that will help employees address any misconstrued prejudice, bigotry, or intolerance.

It is important to also keep in mind that the degradation caused by homophobia may not always be direct. As Irwin (2007) explained, "[discrimination] need not be conscious or intentional." Also, when considering hospitals or clinics, discrimination may affect not only physicians and staff, but patients. One study found that in the past the LGBT community has underutilized healthcare services out of a fear of discrimination (Puddester, 2008). By not having an educated workforce that is receptive to the needs of queer patients, a hospital or clinic not only prevents people who may be suffering from a physical ailment, but they could essentially forfeit the loss of revenue to the organization.

The loss of potential revenue is only miniscule compared to the harm discrimination has on an employee's morale. It will need to be the consequences of the act on the individual, and not the organization that should always take priority. One of the more difficult forms of discrimination and harassment to overcome by an organization will be against those who do

\footnotetext{
${ }^{2}$ Transgender men and women unfortunately are in many instances unable to maintain "invisibility" in the workplace, especially those in transition due to its lengthy and tedious process.
}

not conform to the traditional gender. Gender incongruity is rarely discussed in classrooms, employee lounges, town hall meetings, and most disturbingly, medical offices (Rudacille, 2006). Some medical schools are moving towards adding educational instruction to include proper treatment of lesbian, gay, and bisexual patients, but very few are including in depth training on how to effectively treat transgender and intersexual patients. Studies are finding that many transgender and gender non-conforming persons are simply unable to find medical facilities that are receptive to their gender variance (Kenagy, 2005; Herbst, et al., 2008)

Another form of harassment for an administrator to have control over is language and expressions used by employees (Presgraves, 2010). It is important to consider the language being used by administration and clinical staff. Accurate terminology is crucial when referring to the LGBT community. It is acceptable for employees to have questions, however, employees and managers must be sensitive in the way that they frame a question; otherwise the question could be interpreted negatively. Questions towards someone who identifies as LGBT will be experienced differently depending on the individual. Questions can be experienced by someone who is queer as "either supportive, warm, and caring or voyeuristic, upsetting, and invasive" (Presgraves, 2010). For example, when conversing with someone who identifies as transgender, avoid sentences such as "Does this mean you're gay?" or "Are you a boy or girl?" or "Will you always be this way?" Instead, consider asking "I'm wondering about a few things. Is this a good time and safe place to talk?" (McNaught, 2010; Presgraves, 2010). The question comes off as supportive and open, and implies that the questioner understands the need for privacy.

Apt labels can make all the difference. Pronouns and gender neutral terms are necessary to eliminating heterosexism. This will come in handy when including queer employees in group conversations. For instance, try avoiding "he" or "she," use "partner" instead of "husband" or "wife," or when addressing a transgender employee, be sure to use the appropriate gender identity, even if you know that the person was born the opposite of what they identify. Appropriate labeling will help to eliminate the feeling of invisibility that many LGBT members have expressed in a business environment (Fassengir, 1991; McNaught, 2010). Using proper labeling will also appeal to your patients, many of whom may also identify as queer. It will be inevitable for an appropriate labeling to be used during a conversation with a LGBT employee, so it is imperative that employees acutely understand what they are asking their LGBT cohorts. If they do not understand, or it is something they could possibly research or read on their own, then the question should probably be avoided. Furthermore, keep in mind that in the beginning when an employee is explicitly out, it is inevitable that other employees will experience some anxiety and awkwardness. As a human resource manager, it should be known that what is typically found is not hostility but an "ignorance-based anxiety" amongst employees (McNaught, 2010). This is combatable, but it will take a substantial effort through diversity trained human resource managers to educate supervisors and colleagues on sexual orientation and gender identity.

Other than proper terminology, positive practices should be implemented into hospitals and clinics to promote LGBT 
diversity. As Sprinks (2013) reports, a number of hospitals have begun flying rainbow colored flags (the international symbol for advocacy of LGBT rights) to demonstrate their support for queer rights, while others have reported encouraging their staff to participate in local Pride events or to take part in the annual International Month Against Homophobia and Transphobia. Some facilities have even held their own LGBT discrimination awareness events in the workplace to advocate for staff and patients. If subtlety is preferred, then try encouraging your staff to wear rainbow colored pins or tags, include gay and lesbian literature in the waiting room, or incorporate gender neutral bathrooms into the building.

The healthcare field is now in a position to emulate what many other organizations are beginning to do-embracing diversity of its queer population through education and training. Intel has created "Chartered Employee Groups" in assisting employees to unite around a significant common affinity of their personal identity and support these groups through leadership activities and training. More than half of Fortune 500 companies now offer domestic partnership benefits (reported by the New York Times, 2005).

Very soon the healthcare industry will be held to the same standard of LGBT inclusion that is now being witnessed in other industries. Future health administrators are going to be required to restructure their workplace culture to openly embrace queer employees. To not do so, is a disservice to both the employees and the patients.

\section{References}

Anne Jilson, I. (2002). Opening closed doors: Improving access to quality health services for LGBT populations. Clinical Research and Regulatory Affairs, 19(2), 153.

Blumenfeld, W. (1992). Homophobia: How we all pay the price. Boston, MA: Beacon Press.

Brown, M., \& Rounsley, C. (2003). True selves: Understanding transexualism--for families, friends, coworkers, and helping professiaonals. San Francisco: Jossey-Bass Publishers.

Chung, Y. (2001). Work discrimination and coping strategies: Conceptual frameworks for counseling lesbian, gay, and bisexual clients. The Career Development Quarterly, 50, $33-42$.

Chung, Y., Williams, W., \& Dispenza, F. (2009). Validating work discrimination and coping strategy models for sexual minorities. The Career Development Quarterly, 58, 162170.

Donovan, T., \& Tolbert, C. (2013). Do popular votes on rights create animosity toward minorities? Political Research Quarterly, 66(4), 910-922.

Fassinger, R. (1991). The hidden minority: Issues and challenges in working with lesbian women and gay men. The Counseling Psychologist, 19, 157-176.

Griffin, P. (1992). From hiding out to coming out: Empowering lesbian and gay educators. In K. Harbeck, Coming out of the classroom closet (pp. 167-192). NY, Binghamton: Harington Park Press.

Herbst, J., E, J., T, F., V, M., M, N., \& Crepaz, N. (2008). Estimating HIV prevalence and risk behaviors of transgender persons in the United States: A systematic review. AIDS Behav, 51(1), 183-202.
Herman, J. (2009). Transgender eplained for those who are not. Bloomington, Indiana: AuthorHouse.

Kenagy, G. (2005). Transgender health: Findings from two needs assessment studies in Philadelphia. Health Social Work, 53(4), 19-26.

Levine, M., \& Leonard, R. (1984). Discrimination against lesbians in the workforce. Journal of Women in Culture and Society, 9, 700-710.

McNaught, B. (1993). Gay issues in the workplace. New York: St. Martin's Press.

McNaught, B. (1997). Now that I'm out, what do I do? Thoughts on living deliberately. New York: St. Martin's Press.

McNaught, B. (2010). Creating a welcoming environment for gay employees. The Diversity Factor, 18(4).

Presgraves, D. (2010, June 24). NYC respect for all training increase staff competency at addressing anti-LGBT bullying. Retrieved 2013, from Gay, Lesbian, and Straight Education Network: http://www.glsen.org/cgibin/iowa/all/library/record/2587.html?state=research\&type =research

Rondahl, G. (2009). Students inadequate knowledge about lesbian, gay, bisexual, and transgender persons. International Journal of Nursing Education Scholarship, 6(1), 1-18.

Rudacille, D. (2006). The Riddle of Gender: Science, Activism, and Transgender Rights. New York: Anchor Books.

Sprinks, J. (2013). 'We want a culture where it is okay for people to be who they are'. Nursing Standard, 27(23), 1213.

Wagner, S., Greco, F., Hoda, M., Inferrera, A., Lupo, A., Hamza, A., \& Fornara, P. (2010). Male-to-Female transsexualism: Technique, results and 3-Year follow-up in 50 patients. Urologia Internationalis, 84, 330-333. 